\title{
Biomarkers and polymorphisms in pancreatic neuroendocrine tumors treated with sunitinib
}

\author{
Paula Jiménez-Fonseca ${ }^{1}$, Miguel Navarro Martín², Alberto Carmona-Bayonas ${ }^{3}$, \\ Alfonso Calvo ${ }^{4}$, Javier Fernández-Mateos ${ }^{5}$, Miriam Redrado 6 , Jaume Capdevila7, \\ Nieves Martínez Lago ${ }^{8}$, Adelaida Lacasta9 ${ }^{\text {, Javier Muñarriz }}{ }^{10}$, Ángel Segura ${ }^{11}$, Josep \\ Fuster $^{12}$, Francisco Barón ${ }^{13}$, Marta Llanos $^{14}$, Raquel Serrano ${ }^{15}$, Alfredo Castillo ${ }^{1}$, \\ Juan Jesús Cruz Hernández ${ }^{2}$ and Enrique Grande ${ }^{16}$

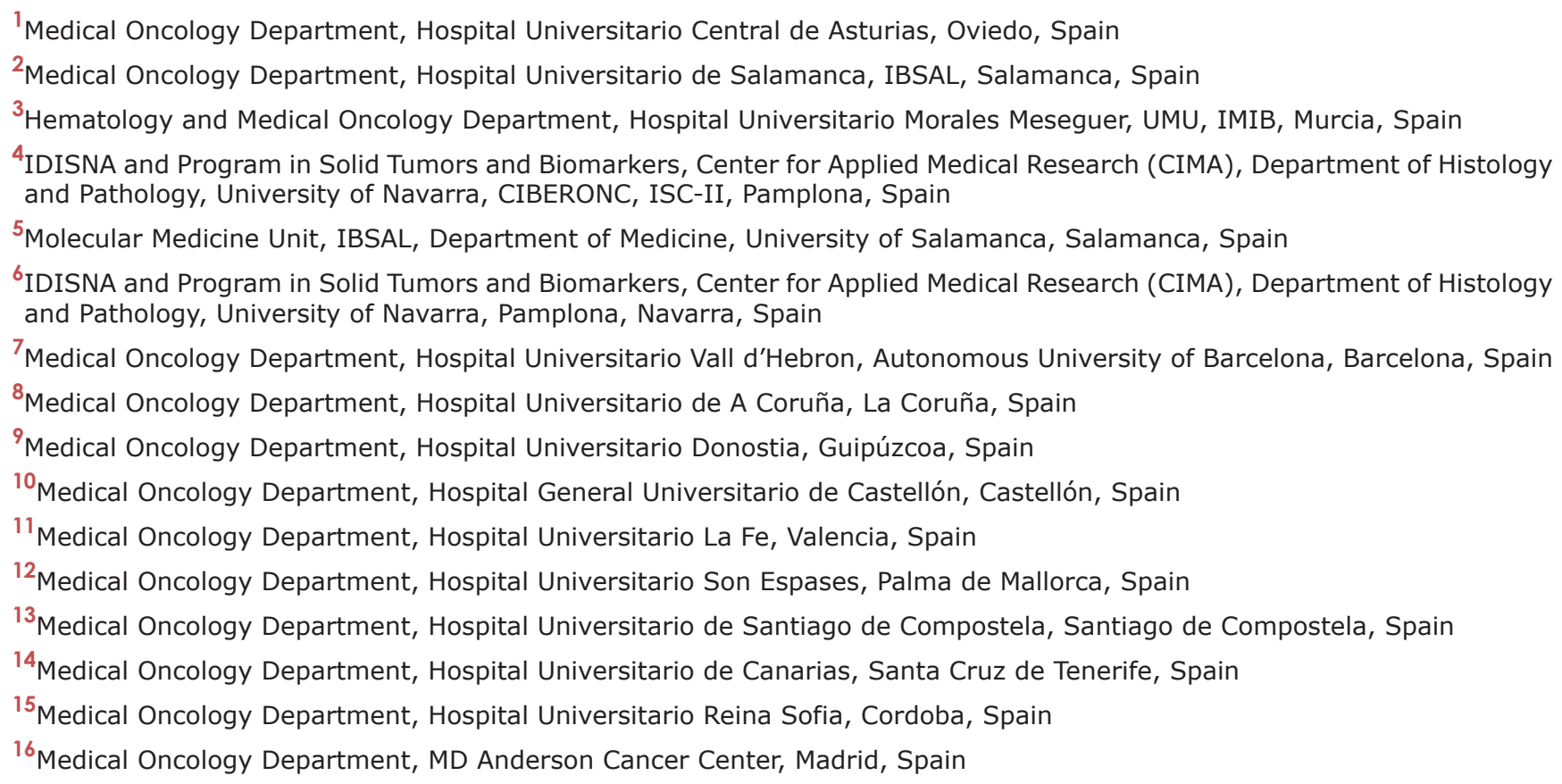

Correspondence to: Paula Jiménez-Fonseca, email: palucaji@hotmail.com

Keywords: sunitinib; osteopontin; IL-6; VEGFR-3; pancreatic neuroendocrine tumors

Received: September 13,2018 Accepted: October 31,2018Ｐublished: December 11, 2018

Copyright: Jiménez-Fonseca et al. This is an open-access article distributed under the terms of the Creative Commons Attribution License 3.0 (CC BY 3.0), which permits unrestricted use, distribution, and reproduction in any medium, provided the original author and source are credited.

\section{ABSTRACT}

Several circulating biomarkers and single nucleotide polymorphisms (SNPs) have been correlated with efficacy and tolerability to antiangiogenic agents. These associations remain unexplored in well-differentiated, metastatic pancreatic neuroendocrine tumors treated with the multitargeted tyrosine kinase inhibitor sunitinib. We have assessed the effect on tumor response at 6 months, overall survival, progression-free survival and safety of 14 SNPs, and 6 soluble proteins. Forty-three patients were recruited. Two SNPs in the vascular endothelial growth factor receptor 3 (VEGFR-3) gene predicted lower overall survival: rs307826 with hazard ratio (HR) 3.67 (confidence interval [CI] 95\%, 1.35-10.00) and rs307821 with HR 3.84 (CI 95\%, 1.47-10.0). Interleukin-6 was associated with increased mortality: HR 1.06 (CI 95\%, 1.01-1.12), and osteopontin was associated with shorter PFS: HR 1.087 (1.01-1.16), independently of Ki-67. Furthermore, levels of osteopontin remained higher at the 
end of the study in patients considered non-responders: $38.5 \mathrm{ng} / \mathrm{mL}$ vs. responders: $18.7 \mathrm{ng} / \mathrm{mL}$, $\mathrm{p}$-value $=0.039$. Dynamic upward variations were also observed with respect to IL-8 levels in sunitinib-refractory individuals: $28.5 \mathrm{pg} / \mathrm{mL}$ at baseline vs. $38.3 \mathrm{pg} / \mathrm{mL}$ at 3 months, $\mathrm{p}$-value=0.024. In conclusion, two VEGFR-3 SNPs as well as various serum biomarkers were associated with diverse clinical outcomes in patients with well-differentiated pancreatic neuroendocrine tumors treated with sunitinib.

\section{INTRODUCTION}

Pancreatic neuroendocrine tumors (PNETs) represent a heterogeneous group of neoplasms arising from pancreatic islets, with an incidence of $<2$ per 100000 persons per year [1]. In the case of welldifferentiated (G1/2), metastatic PNETs, evolution is generally indolent compared to adenocarcinoma of the pancreas [2]. One of its most salient biological traits is its extraordinary vascularization, which is associated with the expression of multiple proangiogenic molecules, such as vascular endothelial growth factor receptors (VEGFR) and platelet-derived growth factor (PDGF) or fibroblast growth factors (FGFs) [3]. The overexpression or activation of proangiogenic pathways (e.g., upregulation of hypoxia-response transcription factors, genes of cellular response to hypoxia, the VEGF/VEGFR axis and crosstalk between pericytes and endothelial cells involving VEGF and PDGF) promotes growth in PNETs by directly upregulating angiogenesis, in addition to other indirect mechanisms $[4,5]$. Additionally, the phosphatidilinositol-3-kinase (PI3K)-AKT-mTOR (mammalian target of rapamycin) pathway acts as the central hub for several cell programs in PNETs, including the participation in complex crosstalk regulating VEGF synthesis [6]. Indeed, the use of mTOR inhibitors is able to prolong progression-free survival (PFS) in advanced PNETs [7].

Among the angiogenesis inhibitors tested in PNETs, sunitinib malate (Sutent, Pfizer) is an oral, multitargeted tyrosine kinase inhibitor (TKI) primarily targeting VEGFR-1, VEGFR-2, VEGFR-3, RET,stem-cell factor receptor (c-kit), and PDGFR- $\alpha / \beta$. In the SUN-1111 study, a phase III clinical trial in patients with well-differentiated PNETs in progression, sunitinib $37.5 \mathrm{mg}$ /day increased PFS compared to placebo (11.4 versus 5.5 months; hazard ratio [HR], 0.42; $<<0.001)$, with an objective response rate of $9.3 \%$ and a favorable safety profile [8]. Certain germline single-nucleotide polymorphisms (SNPs) in VEGFR-3, VEGFA, interleukin-8 (IL-8), FGFR2, c-KIT, or PDGFB have been correlated with clinical outcomes in subjects receiving sunitinib $[9,10]$. In addition, various SNPs in genes that participate in metabolic pathways, efflux transporters and cell detoxification, such as ATPbinding cassette sub-family $B$ member 1 (ABCB1), Nuclear Receptor Subfamily 1 Group I Member 2 (NR1I2) and cytochrome P450 (CYP3A5), might be associated with its therapeutic efficacy or toxicity $[9,11]$. However, no subgroup effect was noted in the SUN-1111 trial and, consequently, to date, no validated biomarker has been able to be incorporated into clinical practice for use in PNETs.

Furthermore, this high angiogenic profile is associated with the secretion of a repertoire of soluble molecules (e.g., proangiogenic cytokines and growth factors) that might be predictive biomarkers involved in the development of resistance to antiangiogenic drugs $[12,13]$.

In this situation, we have designed a prospective, multicenter study (Search activity in the laboratory for sunitinib, SALSUN) to identify biomarkers and SNPs involved in the efficacy or tolerability of sunitinib in patients with well-differentiated PNETs with metastatic disease in progression.

\section{RESULTS}

\section{Patients}

Forty-three patients treated between November 2012 and February 2015 were recruited; the follow-up database was closed in October 2017. All were evaluable for efficacy and safety endpoints, although SNPs were not available for two patients. Patients' baseline clinical characteristics are summarized in Table 1. In particular, sunitinib was administered as first-line treatment in $41.9 \%(\mathrm{n}=18)$, as second-line in $34.9 \%(\mathrm{n}=15)$, and as successive lines in the remaining subjects. The starting dose of sunitinib was $37.5 \mathrm{mg}$ per day. Subjects remained on treatment with sunitinib for a median of 6.3 months (range, 0.2-29); at six months, $37 \%$ of them $(n=16)$ had discontinued treatment: $56.3 \%(\mathrm{n}=9)$ due to progression, $18.8 \%(n=3)$ because of toxicity, and the remaining $25.0 \%$ $(\mathrm{n}=4)$ for another reason. The median follow-up was 51.3 months (95\% confidence Interval [CI]), 44.2-58.3). In the population evaluable for efficacy endpoints $(n=43), 40$ progression events (93\%) were detected and median PFS was 12.0 months ( $95 \%$ CI, 7.2-16.7). Moreover, 40 deaths $(93 \%)$ were recorded with a median OS of 53.5 months (95\% CI, 45.4-61.6).

As for the objective response rate at 6 months $(\mathrm{n}=41)$, no patient attained a full response; $6(14.6 \%)$ exhibited partial response; $30 \quad(73.2 \%)$ displayed stable disease, and 5 individuals $(12.2 \%)$ progressed. Consequently, the rate of clinical benefit was $87.8 \%$ $(n=36)$. In the population suitable for analysis for safety 
Table 1: Baseline characteristics of the patients

\begin{tabular}{|c|c|}
\hline & Patients, $N=43$ \\
\hline Sex (female) & $20(46.5 \%)$ \\
\hline Age (median, range) & $56(28-77)^{*}$ \\
\hline \multicolumn{2}{|l|}{ ECOG-PS } \\
\hline $\mathbf{0}$ & $24(55.8 \%)$ \\
\hline 1 & $19(44.2 \%)$ \\
\hline \multicolumn{2}{|l|}{ Location of the tumor } \\
\hline Head & $12(27.9 \%)$ \\
\hline Head and body & $1(2.3 \%)$ \\
\hline Tail & $16(37.2 \%)$ \\
\hline Tail and body & $4(9.3 \%)$ \\
\hline Body & $2(4.6 \%)$ \\
\hline NR & $6(13.9 \%)$ \\
\hline \multicolumn{2}{|l|}{ Tumor stage } \\
\hline Locally advanced & $1(2.3 \%)$ \\
\hline Metastatic & $42(97.7 \%)$ \\
\hline \multicolumn{2}{|c|}{ Number of metastatic locations } \\
\hline 1 & $22(51.1 \%)$ \\
\hline 2 & $15(34.8 \%)$ \\
\hline 3 & $1(2.3 \%)$ \\
\hline 4 & $3(6.9 \%)$ \\
\hline NR & $2(4.6 \%)$ \\
\hline \multicolumn{2}{|l|}{ Metastatic locations } \\
\hline Lung & $1(2.3 \%)$ \\
\hline Nodes & $13(30.2 \%)$ \\
\hline Bone & $4(9.3 \%)$ \\
\hline Liver & $40(93.0 \%)$ \\
\hline Others & $5(11.6 \%)$ \\
\hline Functioning tumor & $6(13.9 \%)$ \\
\hline Concurrent SSA & $19(44.1 \%)$ \\
\hline \multicolumn{2}{|l|}{ Prior treatments } \\
\hline None & $18(41.8 \%)$ \\
\hline SSA & $13(30.2 \%)$ \\
\hline Chemotherapy & $6(13.9 \%)$ \\
\hline SSA and chemotherapy & $5(11.6 \%)$ \\
\hline SSA and radiotherapy & $1(2.3 \%)$ \\
\hline \multicolumn{2}{|l|}{ Ki-67 index } \\
\hline$<3$ & $9(20.9 \%)$ \\
\hline 3-10 & $16(37.2 \%)$ \\
\hline $11-20$ & $12(27.9 \%)$ \\
\hline NR & $6(13.9 \%)$ \\
\hline
\end{tabular}

The percentage refers to columns. ${ }^{*}$ The datum for age expresses the median and range. Abbreviations: $\mathrm{N}=$ sample size, NR = not reported, ECOG-PS = Eastern Cooperative Group Performance Status, SSA = somatostatin analogue. 
endpoints $(n=43)$, the most common grade $1-4$ toxicities were asthenia $(n=31 ; 72 \%)$, diarrhea $(n=22 ; 51 \%)$, hypothyroidism $(n=9 ; 21 \%)$, neutropenia $(n=18 ; 42 \%)$, hand-foot syndrome $(\mathrm{n}=13 ; 30 \%)$, arterial hypertension $(n=13 ; 30 \%)$, and thrombocytopenia $(n=8 ; 19 \%)$. There was only a single case of grade 4 toxicity (diarrhea). Dose reduction due to toxicity was required in 16 patients $(37 \%)$. The breakdown of the severity of these toxicities is shown in Supplementary Table 1.

Of the 43 evaluable patients, a sample for genotyping SNPs was available for 41 (1 patient was randomly lost to follow-up and another sample was hemolyzed on receipt). Supplementary Table 2 presents the SNPs analyzed and allele frequencies, all of which were compatible with the Hardy and Weinberg equilibrium, $p>0.05$. As for circulating biomarkers, blood samples for baseline determination were received for 36 of 43 subjects $(83 \%)$; in the remaining cases $(n=7)$, material was not available either because there was insufficient blood or tubes were missing. At three months, 31 blood samples were available (two individuals died before sampling; three were missing for purely administrative reasons). At the end of the study, we had four additional drop-outs (two due to severe clinical impairment, two missing values for administrative reasons).

\section{Effect of polymorphisms on the rate of clinical benefit, PFS, and OS}

Table 2 displays the results of Cox's PH regression for survival endpoints (PFS/OS) and binary logistic regression for clinical benefit. Two polymorphisms related to angiogenesis were significantly associated with OS: VEGFR-3 c. 1480A > G (rs307826) with HR 3.67 (CI 95\%, 1.35-10.00), and VEGFR-3 c.4202G $>$ T (rs307821) with HR 3.84 (CI 95\%, 1.47-10). The wild-type genotype of VEGFR-3 was associated with increased median overall survival (OS) (49 months; 95\% CI, 28-71) compared to the 29 months, (CI 95\% CI, 8-50) for rs307821 GT/ TT allele variants (Log Rank, $p=0.027$ ) (see Figure 1). None of the genotypes analyzed were associated with the probability of objective response, clinical benefit or PFS (Table 2). Insofar as safety data are concerned, the only predictive factor associated with a higher percentage of dose reductions was the VEGFR-3 rs307826 SNP. Thus, the dose was lowered in the first 6 months in $21 \%$ of the homozygous wild-type subjects vs. 59\% in patients with the other genotypes; odds ratio (OR) 5.33 (CI 95\%, 1.20-23.65), $p=0.027$ (see Table 3). Patients with variant VEGFR-3 alleles (rs307821) had a higher rate of hypothyroidism: $45 \%$ vs. 36\%, OR 5.41 (CI 95\%, 1.10 26.46), $p=0.041$. No other SNP was found to be associated with toxicity (of any type) or with antiangiogenic side effects (Table 3). No differences were detected in treatment duration based on the SNPs analyzed. None of these tests was significant after applying Holm-Bonferroni correction.

\section{Effect of circulating biomarkers on response and survival endpoints}

Possible temporary, sunitinib-sensitivity dependent variations were analyzed (see Table 4). All $p$-values were Holm-Bonferroni corrected. A significant increase was noted in IL-8 levels in subjects with progressive disease at 3 months: $28.5 \mathrm{pg} / \mathrm{mL}$ (interquartile range [IQR], 30.9) at baseline vs. $38.3 \mathrm{pg} / \mathrm{mL}(\mathrm{IQR}, 41.0)$, $p$-value=0.024. In contrast, responders did not exhibit dynamic changes: 13.7 $\mathrm{pg} / \mathrm{mL}$ (IQR, 1.86) at baseline vs.12.6 pg/mL (IQR, 20.28) at 3 months, $p$-value $=0.345$. Similarly, baseline levels of sE-selectin decreased at 3 months in both responders and non-responders $(p<0.001)$, but then increased at the end of the study (see Table 4). We observed other tendencies but dynamic differences could not be statistically confirmed for the remaining biomarkers during follow-up (see Table 4); for instance, TIMP-1 levels were 30.5\% lower in subjects with response versus $10.1 \%$ higher in patients who did not achieve response, $p$-value $=0.21$ (Figure 2D).

Median levels of proinflammatory cytokines (IL-6 and IL-8), HGF, and OPN tended to be lower at the end of the study in individuals exhibiting tumor response in comparison with subjects with no response (see Figure $2 \mathrm{~A}, 2 \mathrm{~B}, 2 \mathrm{C} \& 2 \mathrm{E})$. However, after adjusting for the family-wise error associated with multiple comparisons, none were significant ( $p$-value $>0.05$ for all). In the case of IL-6, circulating levels remained all but undetectable in patients displaying tumor response throughout the entire follow-up period, with a baseline median of IL-6: 0 (IQR, 2.22) vs. $4.5 \mathrm{pg} / \mathrm{mL}(\mathrm{IQR}, 5.1$ ), $p$-value $=0.072$ (see Figure 2D). However, absolute levels of TIMP-1 and sE-Selectin were not significantly different at any point during followup for subjects with or without response (see Figure 2A, 2B, 2C and 2D).

Finally, we analyzed whether the dynamic changes (reduction vs. increase) in each of the soluble markers exerted any effect on OS-related endpoints in addition to the Ki-67 index (see Supplementary Tables 4 \& 6). Multiple comparison adjustments were not applied for time-to-event analyses, due to their exploratory purpose. Only IL-6 levels (pg/mL, continuous time-dependent variable) were significantly associated with increased mortality, with a HR of 1.068 (CI 95\%, 1.013-1.126), $p$-value $=0.013$. The effect was similar when restricted to baseline measures with HR 1.184 (CI 95\%, 1.061-1.321), $p$-value $=0.018$. Similarly, OPN levels were associated with lower PFS, independent of the Ki67\% index, with HR 1.087 (1.011$1.169), p=0.023$. Ki-67 expression was significantly associated with shorter both PFS and OS, as expected (see Supplementary Tables $3 \& 5$ ). 
Table 2: Effect of polymorphisms on clinical benefit rate, PFS, and OS

\begin{tabular}{lccccccc}
\hline & Reference SNP & \multicolumn{2}{c}{ Clinical benefit } & \multicolumn{2}{c}{ PFS } & OS \\
\cline { 3 - 7 } & ID & OR (95\% CI) & p-value & HR (95\%, CI) & p-value & HR (95\%, CI) & p-value \\
\hline \multirow{2}{*}{ VEGFR3 } & rs307826 & $1.43(0.12-17.52)$ & 0.782 & $1.31(0.64-2.67)$ & 0.464 & $3.67(1.35-10)$ & $\mathbf{0 . 0 1 0}$ \\
& rs307821 & NC & 0.999 & $1.04(0.50-2.18)$ & 0.917 & $3.84(1.47-10)$ & $\mathbf{0 . 0 0 5}$ \\
& rs1570360 & $0.87(0.07-10.93)$ & 0.912 & $1.04(0.49-2.50)$ & 0.926 & $2.38(0.83-7.14)$ & 0.104 \\
VEGFA & rs2010963 & $1.20(0.09-15.09)$ & 0.889 & $0.90(0.44-1.85)$ & 0.784 & $0.82(0.32-2.12)$ & 0.685 \\
& rs699947 & $0.21(0.02-2.68)$ & 0.230 & $1.14(0.52-2.49)$ & 0.745 & $1.02(0.37-2.81)$ & 0.962 \\
IL-8 & rs4073 & $0.87(0.07-10.93)$ & 0.912 & $1.04(0.49-2.18)$ & 0.926 & $2.38(0.83-7.14)$ & 0.104 \\
FGFR2 & rs2981582 & NC & 0.999 & $1.05(0.46-2.40)$ & 0.905 & $1.70(0.58-4.98)$ & 0.333 \\
NR1|2 & rs3814055 & $0.62(0.05-7.57)$ & 0.706 & $1.43(0.70-2.91)$ & 0.329 & $1.41(0.57-3.51)$ & 0.461 \\
c-KIT & rs6554199 & $1.20(0.09-15.09)$ & 0.889 & $0.90(0.44-1.85)$ & 0.784 & $0.82(0.32-2.12)$ & 0.685 \\
PDGFB & rs130650 & NC & 0.999 & $0.54(0.25-1.15)$ & 0.107 & $0.55(0.21-1.40)$ & 0.206 \\
& rs1045642 & NC & 0.999 & $1.85(0.78-4.34)$ & 0.162 & $2.12(0.70-6.66)$ & 0.174 \\
ABCB1 & rs1128503 & $1.51(0.12-19.52)$ & 0.750 & $0.92(0.41-2.08)$ & 0.842 & $0.78(0.28-2.19)$ & 0.642 \\
& rs2032582 & $1.24(0.10-15.51)$ & 0.869 & $0.90(0.41-1.96)$ & 0.790 & $0.72(0.26-2.02)$ & 0.536 \\
CYP3A5 & rs776746 & NC & 0.999 & $0.81(0.34-1.92)$ & 0.625 & $0.57(0.16-2.0)$ & 0.378 \\
\hline
\end{tabular}

The comparison between homozygous wild-type genotype $v s$. other genotypes (used as a reference) are shown.

Abbreviations: $\mathrm{NC}=$ not computable, $\mathrm{PFS}=$ progression-free survival, $\mathrm{HR}=$ hazard ratio, $\mathrm{CI}=$ confidence interval, $\mathrm{OR}=$ odds ratio, $\mathrm{OS}=$ overall survival. An $\mathrm{OR}<1$ indicates that clinical benefit is less likely in subjects with the SNP. $P$-values are derived from bivariate binary logical regression for clinical benefit rate, and Cox proportional hazards regression for survival endpoints; adjusted by Ki67 index. Tests were not corrected for multiple comparisons. The clinical benefit rate is the sum of complete and partial responses and stable disease at 6 months.

\section{DISCUSSION}

This is a prospective, multicenter study of the effect of 14 SNPs and 6 circulating biomarkers on safety and efficacy endpoints in patients with low-grade PNETs (G1/ G2, WHO 2010) who received sunitinib. Basically, the work explores how these profiles modify the prognosis, and potentially influence differential response to this drug.

The reason for conducting this analysis was that certain key aspects of optimal selection of patients with a greater benefit-risk ratio have yet to be formally elucidated. In particular, the pivotal trial (SUN-1111) failed to report the analysis of subgroups based on genetic profiles or in-depth analyses of the evolution of circulating biomarkers according to response to sunitinib, which implied a lack of critical information both regarding key pharmacogenomic aspects of the therapy, as well as about the influence of tumor markers on tumor evolution [8].

The VEGFR-3 axis, through various signalling pathways, has a critical role in cancer progression by regulating different cellular functions such as angiogenesis, tumor growth, proliferation and chemotherapy resistance [14]. Neuroendocrine tumors are also highly dependent on VEGFR-3 signalling, which, in turn, is one of the most important targets of sunitinib [8]. Here, we have found that two missense mutations in VEGFR-3 (rs307826 and rs 307821 ), present respectively in $34 \%$ and $26 \%$ of the participants in this study, are associated with decreased OS. VEGFR-3 c.1480A $>$ G (rs307826) involves the exchange of a residue threonine for alanine, which is associated with a deficit of protein expression [15]. The modification of VEGFR-3 c.4202G>T (rs307821) is likely to have functional implications [9]. In both cases, these changes have previously been linked to decreased PFS in patients with PNETs, treated with pazopanib [16] or other drugs [17]. This has generally been attributed to resistance to tyrosine-kinase inhibitors $[16,18,19]$.

Thus, Beuselinck's renal cancer series reported that rs307826 affected survival outcomes with a median of 31 months of OS for genotype AA vs. 22 months for $\mathrm{AG} / \mathrm{GG}$ variants $(\mathrm{p}=0.013)$ [18]. In contrast, GarcíaDonas et al. reported a series of 89 kidney cancer patients treated with sunitinib without any association with OS [9]. Our data also suggest that a SNP in the VEGFR-3 gene (rs307821) increases the likelihood of developing hypothyroidism in patients treated with sunitinib. The biological mechanism of this correlation is not clear, although a tentative explanation could be the increased 


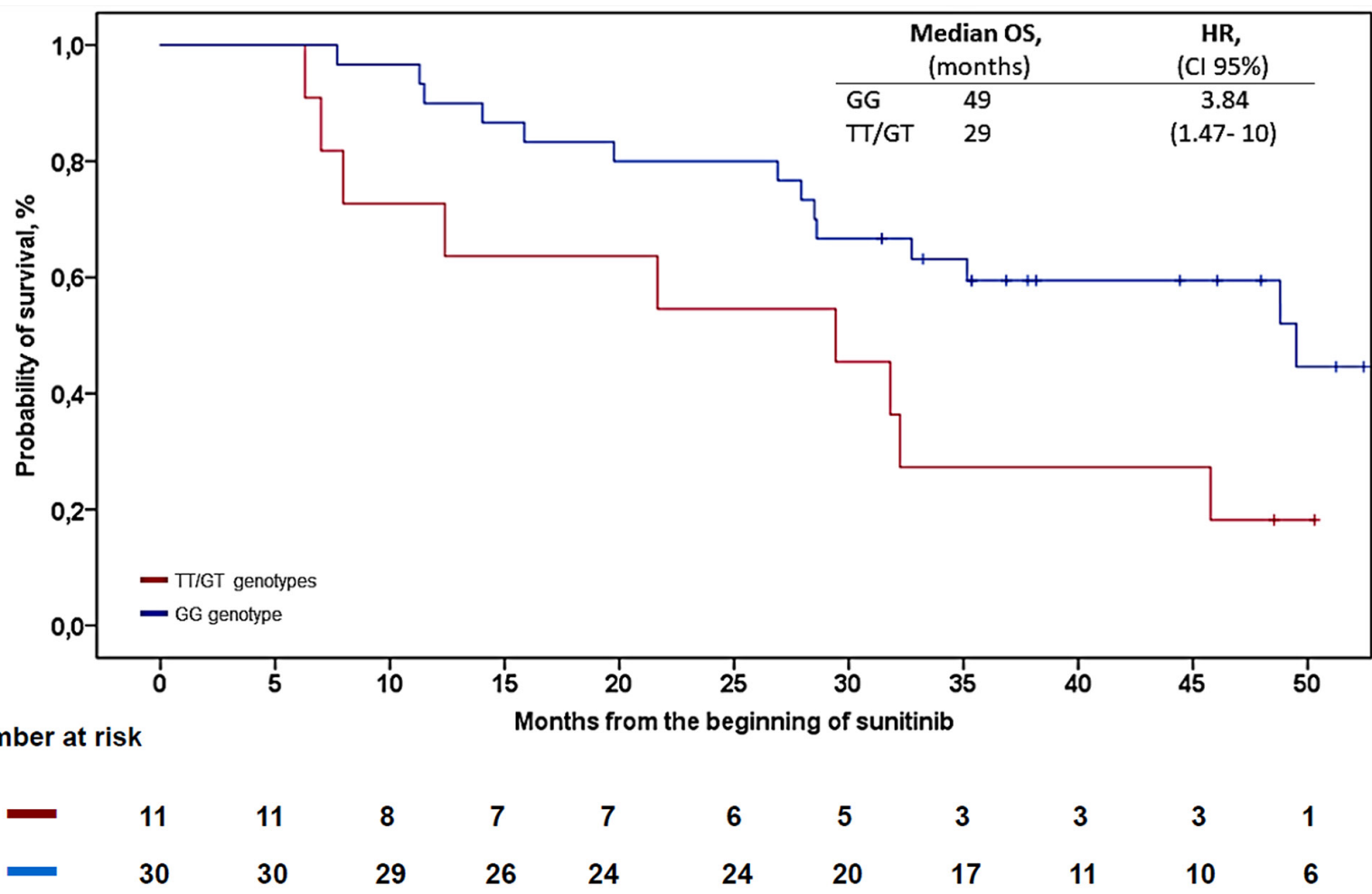

Figure 1: Kaplan-Meier analysis for OS in patients with rs307821. Abbreviations: $\mathrm{OS}=$ overall survival, $\mathrm{HR}=$ hazard ratio, CI $=$ confidence interval.

A

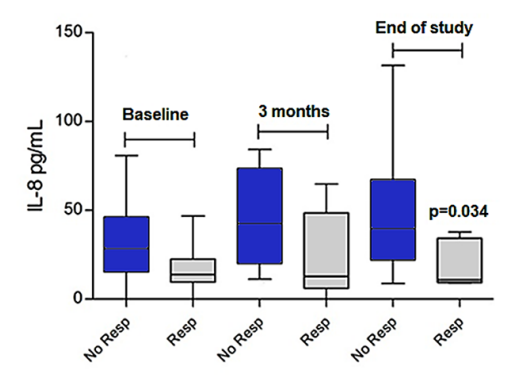

D

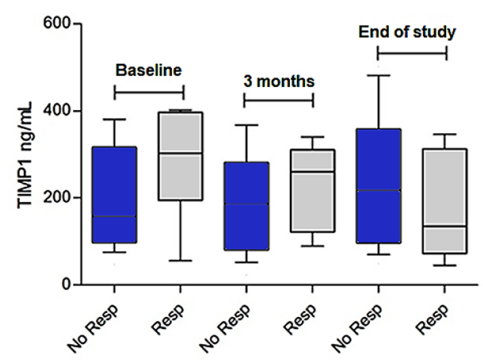

B

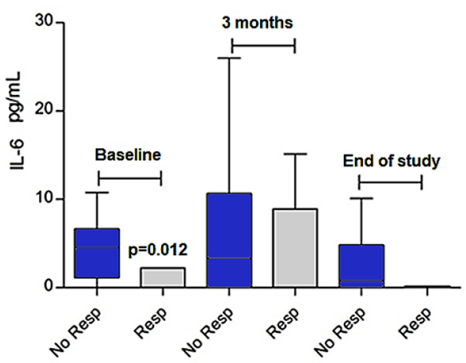

$E$

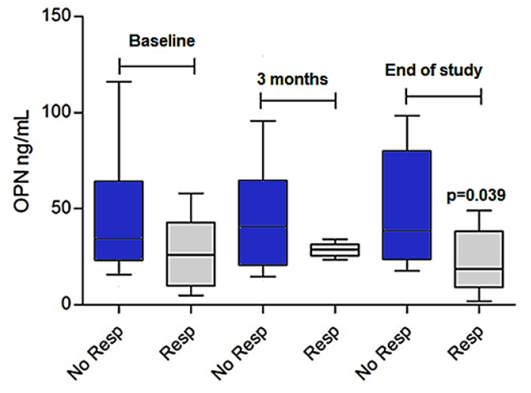

$\mathrm{C}$

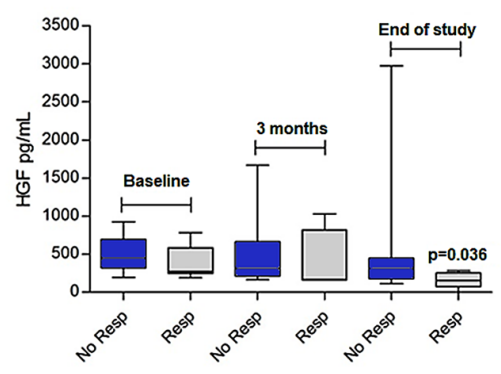

$\mathrm{F}$

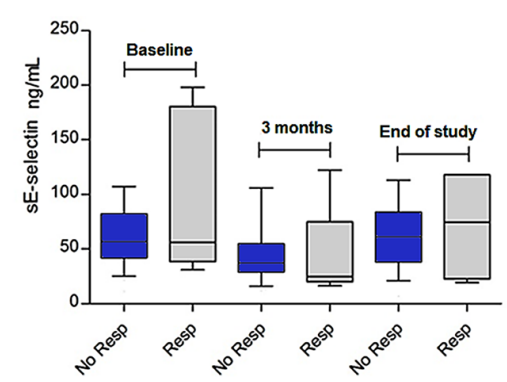

Figure 2: Levels of circulating biomarkers at baseline, three months, and at the end of follow-up. (A) Interleukin-8 (IL8); (B) interleukin-6 (IL-6); (C) hepatocyte growth factor (HGF); (D) tissue inhibitor of metalloproteinase-1 (TIMP-1); (E) osteopontin $(\mathrm{OPN})$ and $(\mathbf{F})$ sE-selectin $P$-values are derived from U-Mann Whitney tests to compare differences between subjects who responded (Resp.) and those who did not respond to treatment (No resp.). Blood samples were available for baseline determinations in 36 patients (30 non-responders, 6 responders); at three months in 31 patients ( 26 non-responders, 5 responders); and 27 subjects at the end of the study (22 non-responders, 5 responders). Responders were those with complete or partial response; non-responders are those with tumor progression or stabilization at 3 months. 
Table 3: Genetic factors related to dose reductions and adverse effects

\begin{tabular}{|c|c|c|c|c|c|c|c|c|c|c|c|c|c|}
\hline & \multirow[t]{2}{*}{$\begin{array}{c}\text { Reference } \\
\text { SNP ID }\end{array}$} & \multicolumn{2}{|c|}{$\begin{array}{l}\text { Dose reductions } \\
\text { due to toxicity }\end{array}$} & \multicolumn{2}{|c|}{ Hypertension } & \multicolumn{2}{|c|}{$\begin{array}{l}\text { Hand-foot } \\
\text { syndrome }\end{array}$} & \multicolumn{2}{|c|}{ Hypothyroidism } & \multicolumn{2}{|c|}{ Mucositis } & \multicolumn{2}{|c|}{ Diarrhea } \\
\hline & & $\begin{array}{c}\text { OR } \\
(95 \%, \mathrm{CI})\end{array}$ & P-value & $\begin{array}{c}\text { OR } \\
(95 \%, C I)\end{array}$ & & $\begin{array}{c}\text { OR } \\
(95 \%, \mathrm{CI})\end{array}$ & P-value & $\begin{array}{c}\text { OR } \\
(95 \%, C I)\end{array}$ & & $\begin{array}{c}\text { OR } \\
(95 \%, C I)\end{array}$ & & $\begin{array}{c}\text { OR } \\
(95 \%, C I)\end{array}$ & P-value \\
\hline \multirow{2}{*}{ VEGFR3 } & rs307826 & $\begin{array}{c}0.15 \\
(0.20-0.82)\end{array}$ & 0.040 & $\begin{array}{c}4.40 \\
(1.05-18.35)\end{array}$ & 0.067 & $\begin{array}{c}2.62 \\
(0.65-10.58)\end{array}$ & 0.277 & $\begin{array}{c}3.19 \\
(0.69-14.66)\end{array}$ & 0.23 & $\begin{array}{c}1.70 \\
(0.46-6.28)\end{array}$ & 0.512 & $\begin{array}{c}1.93 \\
(0.51-7.31)\end{array}$ & 0.509 \\
\hline & rs307821 & $\begin{array}{c}0.25 \\
(0.04-1.37)\end{array}$ & 0.151 & $\begin{array}{c}1.57 \\
(0.36-6.84)\end{array}$ & 0.701 & $\begin{array}{c}1.57 \\
(0.36-6.84)\end{array}$ & 0.701 & $\begin{array}{c}5.41 \\
(1.10-26.46)\end{array}$ & 0.041 & $\begin{array}{c}1.25 \\
(0.31-5.03)\end{array}$ & 1 & $\begin{array}{c}1.75 \\
(0.42-7.25)\end{array}$ & 0.499 \\
\hline \multirow{3}{*}{ VEGFA } & rs 1570360 & $\begin{array}{c}0.77 \\
(0.21-2.79)\end{array}$ & 0.750 & $\begin{array}{c}0.85 \\
(0.21-3.37)\end{array}$ & 1 & $\begin{array}{c}0.52 \\
(0.13-2.06)\end{array}$ & 0.484 & $\begin{array}{c}0.22 \\
(0.04-1.09)\end{array}$ & 0.118 & $\begin{array}{c}0.34 \\
(0.09-1.25)\end{array}$ & 0.120 & $\begin{array}{c}0.55 \\
(0.15-1.99)\end{array}$ & 0.522 \\
\hline & rs 2010963 & $\begin{array}{c}0.56 \\
(0.15-2.01)\end{array}$ & 0.517 & $\begin{array}{c}1.62 \\
(0.39-6.62)\end{array}$ & 0.728 & $\begin{array}{c}1.62 \\
(0.39-6.62)\end{array}$ & 0.728 & $\begin{array}{c}1.55 \\
(0.32-7.34)\end{array}$ & 0.711 & $\begin{array}{c}1.02 \\
(0.28-3.60)\end{array}$ & 1 & $\begin{array}{c}1.05 \\
(0.30-3.65)\end{array}$ & 1 \\
\hline & rs699947 & $\begin{array}{c}1.16 \\
(0.30-4.60)\end{array}$ & 0.824 & $\begin{array}{c}1.35 \\
(0.29-6.20)\end{array}$ & 1 & $\begin{array}{c}0.76 \\
(0.17-3.24)\end{array}$ & 0.999 & $\begin{array}{c}0.78 \\
(0.16-3.82)\end{array}$ & 1 & $\begin{array}{c}2.80 \\
(0.62-12.4)\end{array}$ & 0.296 & $\begin{array}{c}1.23 \\
(0.31-4.73)\end{array}$ & 1 \\
\hline IL-8 & rs 4073 & $\begin{array}{c}0.96 \\
(0.25-3.58)\end{array}$ & 1 & $\begin{array}{c}0.85 \\
(0.21-3.37)\end{array}$ & 1 & $\begin{array}{c}0.52 \\
(0.13-2.06)\end{array}$ & 0.489 & $\begin{array}{c}0.22 \\
(0.04-1.09)\end{array}$ & 0.118 & $\begin{array}{c}0.36 \\
(0.10-1.33)\end{array}$ & 0.194 & $\begin{array}{c}0.96 \\
(0.28-3.30)\end{array}$ & 1 \\
\hline FGFR2 & rs 2981582 & $\begin{array}{c}2.43 \\
(0.54-10.89)\end{array}$ & 0.305 & $\begin{array}{c}2.63 \\
(0.48-14.41)\end{array}$ & 0.295 & $\begin{array}{c}0.76 \\
(0.17-3.24)\end{array}$ & 0.999 & $\begin{array}{c}0.78 \\
(0.16-3.82)\end{array}$ & 1 & $\begin{array}{c}0.98 \\
(0.23-3.86)\end{array}$ & 1 & $\begin{array}{c}0.46 \\
(0.11-1.92)\end{array}$ & 0.324 \\
\hline NR1 $\mid 2$ & rs3814055 & $\begin{array}{c}0.96 \\
(0.26-3.52)\end{array}$ & 1 & $\begin{array}{c}0.80 \\
(0.20-3.12)\end{array}$ & 1 & $\begin{array}{c}0.29 \\
(0.07-1.23)\end{array}$ & 0.162 & $\begin{array}{c}0.29 \\
(0.07-1.23)\end{array}$ & 0.162 & $\begin{array}{c}1.17 \\
(0.32-4.24)\end{array}$ & 1 & $\begin{array}{c}2.03 \\
(0.56-7.31)\end{array}$ & 0.442 \\
\hline c-KIT & rs6554199 & $\begin{array}{c}1.77 \\
(0.50-6.37)\end{array}$ & 0.377 & $\begin{array}{c}1.62 \\
(0.39-6.62)\end{array}$ & 0.728 & $\begin{array}{c}1.62 \\
(0.39-6.62)\end{array}$ & 0.728 & $\begin{array}{c}1.55 \\
(0.32-7.34)\end{array}$ & 0.711 & $\begin{array}{c}1.02 \\
(0.28-3.60)\end{array}$ & 1 & $\begin{array}{c}1.05 \\
(0.30-3.70)\end{array}$ & 1 \\
\hline \multirow[t]{2}{*}{ PDGFB } & rs130650 & $\begin{array}{c}0.64 \\
(0.17-2.47)\end{array}$ & 0.525 & $\begin{array}{c}0.62 \\
(0.13-2.87)\end{array}$ & 0.718 & $\begin{array}{c}1.11 \\
(0.26-4.66)\end{array}$ & 1 & $\begin{array}{c}2.04 \\
(0.44-9.38)\end{array}$ & 0.428 & $\begin{array}{c}0.51 \\
(0.12-2.06)\end{array}$ & 0.498 & $\begin{array}{c}1.60 \\
(0.41-6.118)\end{array}$ & 0.524 \\
\hline & rs 1045642 & $\begin{array}{c}1.64 \\
(0.35-7.69)\end{array}$ & 0.711 & $\begin{array}{c}4.00 \\
(0.73-21.83)\end{array}$ & 0.150 & $\begin{array}{c}1.17 \\
(0.28-4.92)\end{array}$ & 1 & $\begin{array}{c}1.27 \\
(0.21-7.45)\end{array}$ & 1 & $\begin{array}{c}1.41 \\
(0.36-5.44)\end{array}$ & 0.739 & $\begin{array}{c}0.20 \\
(0.03-1.12)\end{array}$ & 0.073 \\
\hline \multirow[t]{2}{*}{ ABCB1 } & rs 1128503 & $\begin{array}{c}0.91 \\
(0.21-3.99)\end{array}$ & 1 & $\begin{array}{c}0.31 \\
(0.07-1.43)\end{array}$ & 0.231 & $\begin{array}{c}2.10 \\
(0.37-11.85)\end{array}$ & 0.462 & $\begin{array}{c}1.27 \\
(0.21-7.45)\end{array}$ & 1 & $\begin{array}{c}3.73 \\
(0.67-20.6)\end{array}$ & 0.152 & $\begin{array}{c}2.12 \\
(0.49-9.19)\end{array}$ & 0.464 \\
\hline & rs2032582 & $\begin{array}{c}0.66 \\
(0.16-2.74)\end{array}$ & 0.718 & $\begin{array}{c}0.22 \\
(0.05-1.01)\end{array}$ & 0.061 & $\begin{array}{c}1.26 \\
(0.26-5.92)\end{array}$ & 1 & $\begin{array}{c}0.72 \\
(0.14-3.61)\end{array}$ & 1 & $\begin{array}{c}4.50 \\
(0.82-24.6)\end{array}$ & 0.085 & $\begin{array}{c}1.60 \\
(0.39-6.50)\end{array}$ & 0.722 \\
\hline CYP3A5 & rs776746 & $\begin{array}{c}1.25 \\
(0.23-6.56)\end{array}$ & 1 & $\begin{array}{c}1.91 \\
(0.35-10.32)\end{array}$ & 0.653 & $\begin{array}{c}0.88 \\
(0.14-5.33)\end{array}$ & 1 & $\begin{array}{c}1.42 \\
(0.22-9.00)\end{array}$ & 1 & $\begin{array}{c}1.09 \\
(0.17-5.88)\end{array}$ & 1 & $\begin{array}{c}0.58 \\
(0.11-3.04)\end{array}$ & 0.682 \\
\hline
\end{tabular}

The comparison between the dominant homozygous model and remaining genotypes (used as reference) is presented. The homozygous wild-type genotype is compared to the rest, referencing toxicities of any grade. $P$-values have been established based on Fisher's exact tests for probability. Abbreviations: $\mathrm{OR}=$ odds ratio, $\mathrm{CI}=$ confidence interval.

vulnerability of the microvasculature of the thyroid gland to VEGFR2 inhibition when the VEGFR-3 signaling pathway is constitutively affected [20].

In line with previous research [21], our data also suggest how baseline levels and dynamic changes of soluble molecules implicated in alternative proangiogenic pathways, proinflammatory mechanisms, cell adhesion or migration (mainly IL-6, IL-8, and sE-selectin) vary differently according to the objective response to sunitinib. One of the most surprising outcomes is the verification that objective responses to sunitinib are accompanied by significantly lower or even undetectable levels of the proangiogenic cytokines IL-8 and IL-6, in line with data obtained in other cancers. In fact, IL-8 is a proangiogenic factor produced by tumor-infiltrating macrophages and other tissues, whose levels rise with exposure to sunitinib in several cancers, including PNETs [13, 22], which would appear to be part of a mechanism of drug resistance [23].

We have also found moderate statistical evidence that elevated OPN levels shortened PFS in this series. OPN is an extracellular protein that mediates interactions with integrins and components of the extracellular matrix, enhances angiogenesis by activating the PI3K/ AKT and ERK pathways [24, 25], which comprises a probable mechanism of acquired active resistance to antiangiogenics in several tumors [26].

Interestingly, we found that IL-6 constitutes an adverse prognostic factor [HR 1.068 (1.013-1.126)], independent of Ki67 index, which may actually help in the prognostic stratification of these tumors [27]. 
Table 4: Levels of biomarkers based on sensitivity to sunitinib

\begin{tabular}{|c|c|c|c|c|c|c|}
\hline & & Baseline & 3 months & End of study & $\begin{array}{c}p \text {-value } \\
(\text { adjusted })^{\S}\end{array}$ & $\begin{array}{c}p \text {-value } \\
\left.\text { (adjusted }^{\ddagger}\right)^{\S \S}\end{array}$ \\
\hline \multirow[t]{2}{*}{$\begin{array}{l}I L-8, \\
p g / m L\end{array}$} & Non-responders & $28.56(30.93)$ & $38.37(41.04)$ & $39.45(42.72)$ & $0.002(0.024)$ & $0.001(0.012)$ \\
\hline & Responders & $13.73(1.86)$ & $12.63(20.28)$ & $10.74(21.00)$ & $0.345(1)$ & $0.224(1)$ \\
\hline \multirow{2}{*}{$\begin{array}{l}I L-6, \\
p g / m L\end{array}$} & Non-responders & $4.55(5.1)$ & $3.33(8.64)$ & $0.75(4.74)$ & $0.180(1)$ & $0.064(0.512)$ \\
\hline & Responders & $0.00(2.22)$ & $0.00(2.73)$ & $0.00(0.00)$ & $0.296(1)$ & $0.317(1)$ \\
\hline \multirow[t]{2}{*}{$\begin{array}{l}H G F \\
p g / m L\end{array}$} & Non-responders & $446.42(346.38)$ & $309.39(450.09)$ & $315.45(266.22)$ & $0.107(0.967)$ & $0.009(0.099)$ \\
\hline & Responders & $273.14(254.01)$ & $162.15(22.02)$ & $154.68(74.40)$ & $0.345(1)$ & $0.080(0.480)$ \\
\hline \multirow[t]{2}{*}{$\begin{array}{l}\text { TIMP-1, } \\
n g / m L\end{array}$} & Non-responders & $158.87(215.97)$ & $186.08(193.94)$ & $218.40(254.65)$ & $0.056(0.560)$ & $0.043(0.430)$ \\
\hline & Responders & $303.20(154.32)$ & $260.57(125.60)$ & $134.65(179.40)$ & $0.136(1)$ & $0.455(0.910)$ \\
\hline \multirow[t]{2}{*}{$\begin{array}{l}O P N, \\
n g / m L\end{array}$} & Non-responders & $34.36(36.88)$ & $40.90(40.14)$ & $38.57(53.58)$ & $0.253(1)$ & $0.654(0.654)$ \\
\hline & Responders & $25.88(26.25)$ & $28.87(1.28)$ & $18.78(11.32)$ & $0.893(1)$ & $0.345(0.690)$ \\
\hline \multirow{2}{*}{$\begin{array}{l}\text { sE- } \\
\text { selectin, } \\
n g / m L\end{array}$} & Non-responders & $56.83(40.14)$ & $36.95(25.78)$ & $60.92(36.37)$ & $0.003(0.033)$ & $0.064(0.576)$ \\
\hline & Responders & $56.03(117.02)$ & $24.52(3.52)$ & $64.09(79.01)$ & $0.068(0.612)$ & $0.068(0.476)$ \\
\hline
\end{tabular}

Responders are those with complete or partial response; non-responders are those with tumor progression or stabilization at 6 months. Paired data were compared with the Wilcoxon Signed-Rank Test. The numbers for the "baseline", "3 months" and "End of Study" columns represent the median, and the interquartile range (in brackets). *Raw p-values and p-values adjusted using the Bonferroni-Holm method (in brackets) for multiple comparisons are displayed. ${ }^{\S}$ Comparison between baseline and 3-month measures. ${ }^{\S}$ Comparison between baseline and exit measures. Abbreviations: IL- $6=$ interleukin-6, IL-8 = interleukin-8, HGF = hepatocyte growth factor, TIMP-1 = tissue inhibitor of metalloproteinase-1, and OPN = osteopontin.

Our data support the finding that dynamic changes in other soluble molecules, such as sE-selectin, would also correlate with acquired resistance to sunitinib in PNETs and could be potential surrogate biomarkers of clinical benefit associated with antiangiogenic therapy in this neoplasm. sE-selectin plays a role in angiogenesis as an adhesion molecule and its effect is capable of modulating response to antiangiogenics, possibly through endothelial cell recruitment, and is a biomarker of VEGF-inhibiting therapies [28, 29].

Our data have limitations, and the reader must be aware that the findings of this hypothesis-generating study call for prospective validation with a larger sample. The absence of a comparator group precludes the assessment of interactions between SNPs and treatment effects. With the limited sample size, this study is underpowered and can hence best be considered as hypothesis-generating. As an example, the power to determine the increase of Il- 8 between baseline and 3 months in the non-responders group by Wilcoxon Signed-Ranked Test is about $43 \%$. When correction for multiple testing is applied for all correlations with the SNPs, none remain significant. However, the Holm-Bonferroni procedure is usually considered a relatively conservative method. As with other studies of SNPs, no pharmacokinetic data are available for sunitinib (or its metabolites) or for VEGF/VEGFR levels to correlate with each one of the genetic variants, though this endpoint would have been compelling. Moreover, concurrent use of SSA in $44 \%$ of patients may introduce an element of uncertainty into the assessment of PFS in this series [30]. Finally, the tumor itself has not been genotyped, which could certainly be informative, although other authors have found a high degree of concordance with the genetic profile of the germ line [31].

In conclusion, the exploratory SALSUN study points to an association between VEGFR-3 SNPs (rs307826 and rs307821) and various serum biomarkers (IL-6 and OPN) involved in alternative proangiogenic 
pathways and mechanisms of resistance, and clinical outcomes during the course of therapy with sunitinib, and might serve as surrogate endpoints in future clinical trials in PNETs. The search for individualized treatment algorithms should be promoted based on genetic variants and biomarkers associated with the signaling pathways of sunitinib targets.

\section{MATERIALS AND METHODS}

\section{Patients}

We have conducted a prospective phase IV study, in 11 Spanish hospitals. All adult patients ( $\geq 18$ years) with a histological diagnosis of well- or moderatelydifferentiated (Ki-67 $\leq 20 \%$ ) metastatic PNET, scheduled to begin treatment with sunitinib as per clinical practice at each center were consecutively enrolled. Other eligibility criteria included the presence of measurable tumor disease by Response Evaluation Criteria In Solid Tumors (RECIST) 1.1 criteria, with confirmed radiological progression in the previous 12 months and adequate hematological, hepatic, and renal function. Subjects had to have an Eastern Cooperative Oncology Group performance status (ECOG-PS) of 0-1 and could not have received prior treatment with $\mathrm{mTOR}$ inhibitors or antiangiogenic agents. Likewise, those individuals with symptomatic brain metastases, prior cardiac events or thromboembolic disease in the previous 12 months were excluded. The study was approved by the Ethic Committee of the Salamanca University Hospital, and all participants provided written informed consent.

\section{Procedures}

Treatment procedures and clinical decisions, including dose reduction policy or management of toxicities, were made by the investigators according to each center's clinical practice. Histopathological and clinical data were collected with an electronic case report form and were regularly monitored externally to guarantee both the quality and safety of the process.

Molecular analyses were performed centrally at two different laboratories, blinded as to clinical or evolutionary data. Fourteen SNPs in 9 genes involved in the pharmacodynamic mechanism, metabolism and detoxification of sunitinib, were evaluated. These SNPs are located in genes that code for cytokines and tyrosine kinase receptors: VEGFR-3 (rs307826, rs307821), VEGFA (rs1570360; rs699947, rs2010963), interleukin-8 (IL-8) (rs4073), FGFR2 (rs2981582), c-KIT (rs6554199), PDGFB (rs3814055) [9, 10], as well as in genes that participate in cell detoxification and drug metabolism: ABCB1 (rs1045642, rs1128503, rs2032582), NR1I2 (rs3814055) and CYP3A5 (rs776746) [9, 10]. These SNPs were chosen following a review of the literature based on: the presence of prior evidence of their association with PFS/OS during treatment with sunitinib or pazopanib, that entailed a switch in the sequence of amino acids and that had minor allele frequencies $\geq 5 \%$ in previous studies [10-18]. With respect to the genes of angiogenesis, we focused on VEGFR-3 because the preclinical evidence suggests that it has a more active role than VEGFR-2 in the development of distant and lymphatic metastases [9]. DNA was isolated from peripheral blood by standard proteinase $\mathrm{K}$ and phenol-chloroform protocols. Blood was stored at $-20^{\circ} \mathrm{C}$ until analysis. Genotyping was performed with Real-Time PCR and TaqMan SNP genotyping assays, using the StepOnePlus ${ }^{\circledR}$ System to detect fluorescence and assign alleles (Applied Biosystems; Foster City, CA).

Simultaneously, hepatocyte growth factor (HGF), interleukin-6 (IL-6), IL-8, tissue inhibitor of metalloproteinase-1 (TIMP-1), sE-selectin, and osteopontin (OPN) levels were determined in patients' blood samples. These molecules were chosen for their putative role in the angiogenic process and/or earlier evidence of sunitinib's effect on their circulating levels [32]. Biomarker levels were quantified by the multiplex bead assays (Luminex xMAP) incorporated into the MILLIPLEX MAP kits and run on Luminex 200, according to the manufacturer's instructions. Samples were drawn at baseline, three months and at the time of patient progression.

\section{Objectives \& variables}

We conducted a hypothesis-generating pilot study to correlate the presence of the afore-named SNPs and the trend of circulating biomarkers in responders and non-responders to sunitinib. Other exploratory objectives included establishing the correlation with clinical benefit and objective response rates, survival-based endpoints (PFS/OS), overall toxicity, class-specific toxicities, and dose reductions due to toxicity. OS was defined as the time elapsed between initiating therapy with sunitinib and the date of death due to any cause, whereas PFS was considered to be the time between treatment initiation until objective progression or demise. In any case, subjects with no event at the end of follow-up were censored. Objective response was evaluated locally by the researchers using RECIST 1.1 every 6 months until progression or withdrawal from the study [33]. Response was not centrally assessed. The rate of clinical benefit was defined as the sum of evaluations with complete or partial response, and stable disease. Adverse events were graded as per the Common Terminology Criteria for Adverse Events (CTCAE), version 3.0 [34]. Since the genotypes identified with homozygous variants were uncommon, we pooled these cases with heterozygous genotypes in the survival analysis. Tumors have been graded by Ki67 index values according to the 2010 WHO classification [35]. 


\section{Statistics}

Hardy-Weinberg equilibrium (HWE) assumption was calculated by Chi-squared test for each SNP. The association between clinical and molecular variables was analyzed by crosstabs and Pearson's chi-squared tests $(\chi 2)$, while odds ratio (OR) and 95\% confident intervals were calculated by logistic regression analyses. OS and PFS-related endpoints were estimated using the Kaplan-Meier method. To evaluate the effect of each SNP for each OS endpoint, Cox's proportional hazards $(\mathrm{PH})$ regression was used, adjusted by Ki67 index. Cytokines and serum biomarkers were treated as time-dependent variables [36]. Fisher's exact test was applied to compare categorical variables. Statistical hypothesis testing for continuous variables was performed using the Mann-Whitney U test (due to the non-normality of these variables). Paired data were compared with the Wilcoxon Signed-Rank Test. All statistical assessments were two-sided and $p$-values $<0.05$ were deemed significant. Given the exploratory nature of the study in a field for which no published data were available during the design phase, no statistical tool was applied to calculate sample size. Furthermore, for the same reason, corrections for multiple comparison were performed only for the effect of circulating biomarkers on response. The SPSS version 19.0 statistical software package was used.

\section{Abbreviations}

ATP-binding cassette sub-family $\mathrm{B}$ member 1 (ABCB1)

Common Terminology Criteria for Adverse Events (CTCAE)

Cytochrome P450 (CYP3A5)

Eastern Cooperative Oncology Group performance status (ECOG-PS)

Fibroblast growth factors (FGFs)

Fibroblast growth factor receptor 2 (FGFR2)

Hazard ratio (HR)

Hepatocyte growth factor (HGF)

Interleukin-6 (IL-6)

Interleukin-8 (IL-8)

Interquartile range (IQR)

mTOR (mammalian target of rapamycin)

Nuclear Receptor Subfamily 1 Group I Member 2

(NR1I2)

Osteopontin (OPN)

Overall survival (OS)

Pancreatic neuroendocrine tumors (PNETs)

Platelet Derived Growth Factor Subunit B (PDGFB)

Phosphatidilinositol-3-kinase (PI3K)

Platelet-derived growth factor (PDGF)

Response Evaluation Criteria In Solid Tumors

(RECIST) 1.1 criteria

Single-nucleotide polymorphisms (SNPs)
Tissue inhibitor of metalloproteinase-1 (TIMP-1)

Vascular endothelial growth factor receptors (VEGFR)

Vascular Endothelial Growth Factor A (VEGFA)

\section{Author contributions}

M.N.M., P.J.F and E.G. developed the project and wrote the first draft of the manuscript. M.R. and A.C. quantified biomarker levels by the multiplex bead assays. J.F.M. and performed SNP genotyping assays. J.C., N.M., A.L., A.S., F.B., M.L., R.S., A.C. and J.C. recruited patients and provided clinical information. The final draft of the manuscript was written by A.C.B, A.C. and M.N.M. with comments from all authors. All authors participated in the interpretation and discussion of data.

\section{ACKNOWLEDGMENTS}

Frederic Villamayor Forcada for his contribution to data analysis and interpretation. Priscilla Chase Duran for her translation and linguistic editing of the text.

\section{Ethics statement}

Research involving human participants: All procedures followed were in accordance with the ethical standards of the responsible committee on human experimentation (institutional and national) and with the Helsinki Declaration of 1964 and later versions. Informed consent or a substitute for it was obtained from all patients before they were included in the study.

\section{CONFLICTS OF INTEREST}

Enrique Grande has received honoraria for advisory boards, meetings, and/or lectures from Pfizer, BMS, IPSEN, Roche, Eisai, Eusa Pharma, MSD, SanofiGenzyme, Adacap, Novartis, Pierre Fabre, Lexicon, and Celgene, and has received unrestricted research grants from Pfizer, AstraZeneca, MTEM/Threshold, Roche, IPSEN, and Lexicon.

Jaume Capdevila has received honoraria for advisory boards and speaker from: Eisai, Bayer, Exelixis, Sanofi, Ipsen, Novartis, Pfizer, Merck, Amgen, Adacap.

Adelaida La Casta has received grants from Amgen and Roche to attend meetings.

Marta Llanos has this disclosures; consultant or advisory role: Amgen, Sanofi; speaker: Bristol, Roche, Servier, Ipsen, Eisai, Pfizer, Lilly; other: Merck, Shire.

\section{FUNDING}

The study was funded by Pfizer in Spain, through a restricted grant to conduct a research project in the field of pancreatic tumors. 


\section{REFERENCES}

1. Hallet J, Law CH, Cukier M, Saskin R, Liu N, Singh S. Exploring the rising incidence of neuroendocrine tumors: a population-based analysis of epidemiology, metastatic presentation, and outcomes. Cancer. 2015; 121:589-97. https://doi.org/10.1002/cncr.29099.

2. Jiménez-Fonseca $P$, Carmona-Bayonas A, MartínPérez E, Crespo G, Serrano R, Llanos M, Villabona C, García-Carbonero R, Aller J, Capdevila J, Grande E, and Spanish Neuroendocrine Tumor Group (GETNE). Health-related quality of life in well-differentiated metastatic gastroenteropancreatic neuroendocrine tumors. Cancer Metastasis Rev. 2015; 34:381-400. https://doi.org/10.1007/s10555-015-9573-1.

3. Teulé A, Martín L, Casanovas O. Relevance of angiogenesis in neuroendocrine tumors. Management of neuroendocrine tumors of the pancreas and digestive tract. Springer; 2014. pp. 29-41. https://doi.org/10.1007/978-2-8178-0430-9_3.

4. Itakura J, Ishiwata T, Friess H, Fujii H, Matsumoto Y, Büchler MW, Korc M. Enhanced expression of vascular endothelial growth factor in human pancreatic cancer correlates with local disease progression. Clin Cancer Res. 1997; 3:1309-16.

5. Zhang J, Jia Z, Li Q, Wang L, Rashid A, Zhu Z, Evans DB, Vauthey JN, Xie K, Yao JC. Elevated expression of vascular endothelial growth factor correlates with increased angiogenesis and decreased progression-free survival among patients with low-grade neuroendocrine tumors. Cancer. 2007; 109:1478-86. https://doi.org/10.1002/cncr.22554.

6. Villaume K, Blanc M, Gouysse G, Walter T, Couderc C, Nejjari M, Vercherat C, Cordier-Bussat M, Roche C, Scoazec JY. VEGF secretion by neuroendocrine tumor cells is inhibited by octreotide and by inhibitors of the PI3K/ AKT/mTOR pathway. Neuroendocrinology. 2010; 91:26878. https://doi.org/10.1159/000289569.

7. Yao JC, Shah MH, Ito T, Bohas CL, Wolin EM, Van Cutsem E, Hobday TJ, Okusaka T, Capdevila J, de Vries EG, Tomassetti P, Pavel ME, Hoosen S, et al, and RAD001 in Advanced Neuroendocrine Tumors, Third Trial (RADIANT-3) Study Group. Everolimus for advanced pancreatic neuroendocrine tumors. N Engl J Med. 2011; 364:514-23. https://doi.org/10.1056/NEJMoa1009290.

8. Raymond E, Dahan L, Raoul JL, Bang YJ, Borbath I, Lombard-Bohas C, Valle J, Metrakos P, Smith D, Vinik A, Chen JS, Hörsch D, Hammel P, et al. Sunitinib malate for the treatment of pancreatic neuroendocrine tumors. N Engl J Med. 2011; 364:501-13. https://doi.org/10.1056/NEJMoa1003825.

9. Garcia-Donas J, Esteban E, Leandro-García LJ, Castellano DE, del Alba AG, Climent MA, Arranz JA, Gallardo E, Puente J, Bellmunt J, Mellado B, Martínez E, Moreno F, et al. Single nucleotide polymorphism associations with response and toxic effects in patients with advanced renal-cell carcinoma treated with first-line sunitinib: a multicentre, observational, prospective study. Lancet Oncol. 2011; 12:1143-50. https://doi.org/10.1016/S1470-2045(11)70266-2.

10. Xu C, Bing N, Ball HA, Sternberg CN, Davis ID, Xue Z, McCann L, King K, Whittaker JC, Spraggs CF, Mooser VE, Pandite LN. Association of germ-line SNPs with overall survival (OS) in pazopanib-treated patients (Pts) with advanced renal cell carcinoma (RCC). J Clin Oncol. 2011; 29:4558-88. https://doi.org/10.1200/jco.2011.29.15_suppl.4558.

11. Diekstra MH, Swen JJ, Boven E, Castellano D, Gelderblom $\mathrm{H}$, Mathijssen RH, Rodríguez-Antona C, GarcíaDonas J, Rini BI, Guchelaar HJ. CYP3A5 and ABCB1 polymorphisms as predictors for sunitinib outcome in metastatic renal cell carcinoma. Eur Urol. 2015; 68:621-29. https://doi.org/10.1016/j.eururo.2015.04.018.

12. Motzer RJ, Hutson TE, Hudes GR, Figlin RA, Martini JF, English PA, Huang X, Valota O, Williams JA. Investigation of novel circulating proteins, germ line single-nucleotide polymorphisms, and molecular tumor markers as potential efficacy biomarkers of first-line sunitinib therapy for advanced renal cell carcinoma. Cancer Chemother Pharmacol. 2014; 74:739-50. https://doi.org/10.1007/s00280-014-2539-0.

13. Zurita AJ, Khajavi M, Wu HK, Tye L, Huang X, Kulke MH, Lenz HJ, Meropol NJ, Carley W, DePrimo SE, Lin E, Wang X, Harmon CS, Heymach JV. Circulating cytokines and monocyte subpopulations as biomarkers of outcome and biological activity in sunitinib-treated patients with advanced neuroendocrine tumours. Br J Cancer. 2015; 112:1199-205. https://doi.org/10.1038/bjc.2015.73.

14. Su JL, Yen CJ, Chen PS, Chuang SE, Hong CC, Kuo IH, Chen HY, Hung MC, Kuo ML. The role of the VEGF-C/ VEGFR-3 axis in cancer progression. Br J Cancer. 2007; 96:541-45. https://doi.org/10.1038/sj.bjc.6603487.

15. Garcia-Donas J, Leandro-García LJ, González Del Alba A, Morente M, Alemany I, Esteban E, Arranz JA, Climent MA, Gallardo E, Castellano DE, Bellmunt J, Mellado B, Puente J, et al. Prospective study assessing hypoxia-related proteins as markers for the outcome of treatment with sunitinib in advanced clear-cell renal cell carcinoma. Ann Oncol. 2013; 24:2409-14. https://doi.org/10.1093/annonc/mdt219.

16. Grande E, Capdevila J, Castellano D, Teulé A, Durán I, Fuster J, Sevilla I, Escudero P, Sastre J, García-Donas J, Casanovas O, Earl J, Ortega L, et al. Pazopanib in pretreated advanced neuroendocrine tumors: a phase II, open-label trial of the Spanish Task Force Group for Neuroendocrine Tumors (GETNE). Ann Oncol. 2015; 26:1987-93. https://doi.org/10.1093/annonc/mdv252.

17. Berardi R, Torniai M, Partelli S, Rubini C, Pagliaretta S, Savini A, Polenta V, Santoni M, Giampieri R, Onorati S, Barucca F, Murrone A, Bianchi F, Falconi M. Impact of vascular endothelial growth factor (VEGF) and vascular endothelial growth factor receptor (VEGFR) single nucleotide polymorphisms on outcome in gastroenteropancreatic neuroendocrine neoplasms. PLoS One. 2018; 13:e0197035. https://doi.org/10.1371/journal.pone.0197035. 
18. Beuselinck B, Karadimou A, Lambrechts D, Claes B, Wolter P, Couchy G, Berkers J, Paridaens R, Schöffski P, Méjean A, Verkarre V, Lerut E, de la Taille A, et al. Single-nucleotide polymorphisms associated with outcome in metastatic renal cell carcinoma treated with sunitinib. $\mathrm{Br} \mathrm{J}$ Cancer. 2013; 108:887-900. https://doi.org/10.1038/bjc.2012.548.

19. Dornbusch J, Walter M, Gottschalk A, Obaje A, Junker K, Ohlmann CH, Meinhardt M, Zacharis A, Zastrow S, Schoffer O, Grimm MO, Klug SJ, Wirth MP, Fuessel S. Evaluation of polymorphisms in angiogenesisrelated genes as predictive and prognostic markers for sunitinib-treated metastatic renal cell carcinoma patients. J Cancer Res Clin Oncol. 2016; 142:1171-82. https://doi.org/10.1007/s00432-016-2137-0.

20. Jang JY, Choi SY, Park I, Park DY, Choe K, Kim P, Kim YK, Lee BJ, Hirashima M, Kubota Y, Park JW, Cheng SY, Nagy A, et al. VEGFR2 but not VEGFR3 governs integrity and remodeling of thyroid angiofollicular unit in normal state and during goitrogenesis. EMBO Mol Med. 2017; 9:750-69. https://doi.org/10.15252/emmm.201607341.

21. Casanovas O, Hicklin DJ, Bergers G, Hanahan D. Drug resistance by evasion of antiangiogenic targeting of VEGF signaling in late-stage pancreatic islet tumors. Cancer Cell. 2005; 8:299-309. https://doi.org/10.1016/j.ccr.2005.09.005.

22. Bello C, Deprimo SE, Friece C, Smeraglia J, Sherman L, Tye L, Baum C, Meropol NJ, Lenz H, Kulke MH. Analysis of circulating biomarkers of sunitinib malate in patients with unresectable neuroendocrine tumors (NET): VEGF, IL-8, and soluble VEGF receptors 2 and 3. J Clin Oncol. 2006 (Suppl 18); 24:4045.

23. Huang D, Ding Y, Zhou M, Rini BI, Petillo D, Qian CN, Kahnoski R, Futreal PA, Furge KA, Teh BT. Interleukin-8 mediates resistance to antiangiogenic agent sunitinib in renal cell carcinoma. Cancer Res. 2010; 70:1063-71. https://doi.org/10.1158/0008-5472.CAN-09-3965.

24. Dai J, Peng L, Fan K, Wang H, Wei R, Ji G, Cai J, Lu B, Li B, Zhang D, Kang Y, Tan M, Qian W, Guo Y. Osteopontin induces angiogenesis through activation of PI3K/AKT and ERK1/2 in endothelial cells. Oncogene. 2009; 28:3412-22. https://doi.org/10.1038/onc.2009.189.

25. Raja R, Kale S, Thorat D, Soundararajan G, Lohite K, Mane A, Karnik S, Kundu GC. Hypoxia-driven osteopontin contributes to breast tumor growth through modulation of HIF $1 \alpha$-mediated VEGF-dependent angiogenesis. Oncogene. 2014; 33:2053-64. https://doi.org/10.1038/onc.2013.171.

26. Gustafsson A, Fritz HK, Dahlbäck B. Gas6-Axl signaling in presence of Sunitinib is enhanced, diversified and sustained in renal tumor cells, resulting in tumorprogressive advantages. Exp Cell Res. 2017; 355:47-56. https://doi.org/10.1016/j.yexcr.2017.03.040.

27. Mizuno R, Kimura G, Fukasawa S, Ueda T, Kondo T, Hara H, Shoji S, Kanao K, Nakazawa H, Tanabe K, Horie S, Oya M, and Tokyo Metropolitan Study Group. Angiogenic, inflammatory and immunologic markers in predicting response to sunitinib in metastatic renal cell carcinoma. Cancer Sci. 2017; 108:1858-63. https://doi.org/10.1111/cas.13320.

28. Ramaswamy B, Elias AD, Kelbick NT, Dodley A, Morrow M, Hauger M, Allen J, Rhoades C, Kendra K, Chen HX, Eckhardt SG, Shapiro CL. Phase II trial of bevacizumab in combination with weekly docetaxel in metastatic breast cancer patients. Clin Cancer Res. 2006; 12:3124-29. https://doi.org/10.1158/1078-0432.CCR-05-2603.

29. Moss MA, Zimmer S, Anderson KW. Role of metastatic potential in the adhesion of human breast cancer cells to endothelial monolayers. Anticancer Res. 2000; 20:1425-33.

30. Carmona-Bayonas A, Jiménez-Fonseca P, Custodio A, Grande E, Capdevila J, López C, Teule A, GarciaCarbonero R, and Spanish Neuroendocrine Tumor Group (GETNE). Optimizing somatostatin analog use in well or moderately differentiated gastroenteropancreatic neuroendocrine tumors. Curr Oncol Rep. 2017; 19:72. https://doi.org/10.1007/s11912-017-0633-2.

31. Kim JJ, Vaziri SA, Rini BI, Elson P, Garcia JA, Wirka R, Dreicer R, Ganapathi MK, Ganapathi R. Association of VEGF and VEGFR2 single nucleotide polymorphisms with hypertension and clinical outcome in metastatic clear cell renal cell carcinoma patients treated with sunitinib. Cancer. 2012; 118:1946-54. https://doi.org/10.1002/cncr.26491.

32. Yuasa T, Takahashi S, Hatake K, Yonese J, Fukui I. Biomarkers to predict response to sunitinib therapy and prognosis in metastatic renal cell cancer. Cancer Sci. 2011; 102:1949-57. https://doi.org/10.1111/j.1349-7006.2011.02054.x.

33. Eisenhauer EA, Therasse P, Bogaerts J, Schwartz LH, Sargent D, Ford R, Dancey J, Arbuck S, Gwyther S, Mooney M, Rubinstein L, Shankar L, Dodd L, et al. New response evaluation criteria in solid tumours: revised RECIST guideline (version 1.1). Eur J Cancer. 2009; 45:228-47. https://doi.org/10.1016/j.ejca.2008.10.026 .

34. Trotti A, Colevas AD, Setser A, Rusch V, Jaques D, Budach V, Langer C, Murphy B, Cumberlin R, Coleman CN, Rubin P. CTCAE v3.0: development of a comprehensive grading system for the adverse effects of cancer treatment. Semin Radiat Oncol. 2003; 13:176-81. https://doi.org/10.1016/S1053-4296(03)00031-6.

35. Nuñez-Valdovinos B, Carmona-Bayonas A, Jimenez-Fonseca P, Capdevila J, Castaño-Pascual Á, Benavent M, Pi Barrio JJ, Teule A, Alonso V, Custodio A, Marazuela M, Segura Á, Beguiristain A, et al. Neuroendocrine Tumor Heterogeneity Adds Uncertainty to the World Health Organization 2010 Classification: Real-World Data from the Spanish Tumor Registry (R-GETNE). Oncologist. 2018; 23:422-32. https://doi.org/10.1634/theoncologist.2017-0364.

36. Fisher LD, Lin DY. Time-dependent covariates in the Cox proportional-hazards regression model. Annu Rev Public Health. 1999; 20:145-57. https://doi.org/10.1146/annurev.publhealth.20.1.145. 